\title{
Síndrome de DRESS: abordaje diagnóstico y terapéutico
}

DRESS syndrome: diagnostic and therapeutic approach

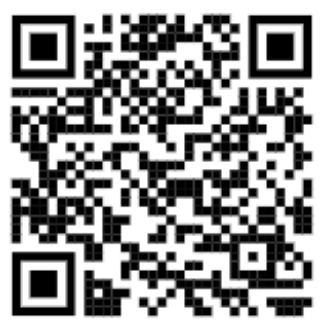

${ }^{1}$ Médico general, graduado de la Universidad de Iberoamérica (UNIBE).

Código médico: 15082

mgc11@hotmail.com.

${ }^{2}$ Médico general, graduado de la Universidad de Iberoamérica (UNIBE).

Código médico: 14717 tatianacorralesm@gmail.com

${ }^{3}$ Médico general, graduado de la Universidad de Iberoamérica (UNIBE).

Código médico: 14727 oscaruj90@gmail.com

\author{
${ }^{1}$ Dr. Marco Tulio Gómez Cerdas \\ Clínica Carlos Duran Cartin, San José, Costa Rica \\ (D) https://orcid.org/0000-0002-5329-3359 \\ ${ }^{2}$ Dra. Tatiana María Corrales Morales \\ Hospital Metropolitano, San José, Costa Rica \\ (iD) https://orcid.org/0000-0003-3727-9968 \\ ${ }^{3} \mathrm{Dr}$. Oscar Ugalde Jiménez \\ Consulthealth, San José, Costa Rica \\ https://orcid.org/0000-0002-2150-4967
}

RECIBIDO

CORREGIDO

ACEPTADO

$25 / 03 / 2019$

05/04/2019

$27 / 04 / 2019$

\section{RESUMEN}

Los medicamentos son elementos que mejoran nuestra calidad de vida de diferentes maneras. Sin embargo, con el uso de los medicamentos podemos tener efectos secundarios relacionados con la interacción entre medicamento-medicamento, medicamentos-alimentos, medicamentos-suplementos, drogas-enfermedades, y por último medicamentos y el cuerpo humano. El síndrome de reacción eosinofílica medicamentosa y síntomas sistémicos es una toxicodermia grave, infrecuente y potencialmente mortal. La cronología abarca un intervalo de tiempo largo entre la toma del medicamento y la aparición de los primeros síntomas (2-8 semanas). Su fisiopatología no está totalmente dilucidada. Intervienen una respuesta inmunitaria contra el medicamento o sus metabolitos en un contexto de susceptibilidad genética (expresada por la asociación a algunos antígenos leucocíticos humanos [HLA] y/o anomalías del metabolismo del medicamento) y una reactivación de virus del grupo herpes (virus herpes humano 6 [VHH-6], VHH-7, virus de Epstein-Barr, citomegalovirus), con una respuesta inmunitaria linfocítica $\mathrm{T}$ dirigida contra estos virus. El diagnóstico de este síndrome se confirma con criterios diagnósticos clínicos y paraclínicos. El tratamiento no está bien estandarizado, pero se basa en la interrupción del presunto medicamento implicado y en una corticoterapia.

PALABRAS CLAVE: síndrome de hipersensibilidad a medicamentos; efectos colaterales y reacciones adversas relacionados con 
medicamentos; anticonvulsivantes; eosinofilia.

\section{ABSTRACT}

Medications are elements that improve our quality of life in different ways. However, with the use of medications we can have side effects related to the interaction between medication-medication, medicationfood, medication-supplements, drugs-diseases, and finally drugs and the human body. The eosinophilic drug reaction syndrome and systemic symptoms, is a serious infrequent and potentially fatal toxicoderma. The chronology covers a long-time interval between the intake of the medication and the appearance of the first symptoms (2-8 weeks). Its pathophysiology is not fully elucidated. An immune response is involved against the drug or its metabolites in a context of genetic susceptibility (expressed by the association of some human leukocyte antigens [HLA] and / or metabolism abnormalities of the drug) and a reactivation of herpes virus (human herpes virus) 6 [VHH-6], VHH-7, Epstein-Barr virus, cytomegalovirus), with a $\mathrm{T}$ lymphocyte immune response directed against these viruses. The diagnosis of this syndrome is confirmed by clinical and paraclinical diagnostic criteria. The treatment is not well standardized, but it is based on the interruption of the presumed medication involved and on corticosteroid therapy.

KEYWORDS: drug hypersensitivity syndrome; drug-related side effects and adverse reactions; anticonvulsants; eosinophilia.

\section{INTRODUCCIÓN}

Los medicamentos son elementos que mejoran nuestra calidad de vida de diferentes maneras. Entre sus beneficios se encuentran brindar analgesia, mantener una armonía en las funciones de nuestros órganos y sistemas tales como el caso de la hipertensión arterial, diabetes mellitus, epilepsia, entre otros. Sin embargo, el uso de los medicamentos no está exento de problemas, podemos tener efectos secundarios relacionados con la interacción entre medicamentomedicamento, medicamentos-alimentos, medicamentos - suplementos, drogas enfermedades, y por último medicamentos y el cuerpo humano. Los efectos secundarios, son efectos no deseados causados por los medicamentos que pueden ser leves (en su mayoría) así como severas (efectos sistémicos). Un tipo de efecto secundario de los medicamentos son las alergias y las reacciones en la piel, como urticaria y erupciones cutáneas (1).

El síndrome de reacción eosinofílica medicamentosa y síntomas sistémicos o síndrome de DRESS (acrónimo del inglés Drug Reaction with Eosinophilia and Systemic Symptoms) o como es conocida en territorio oriental síndrome de hipersensibilidad inducida por fármacos (acrónimo del inglés DrugInduced Hypersensitivity Syndrome DIHS), es una toxicodermia grave, infrecuente y potencialmente mortal. La gravedad está relacionada con la aparición de manifestaciones sistémicas que pueden evolucionar hacia un cuadro 
de insuficiencia multiorgánica, con el agravante de que puede seguir evolucionando aun después de haber sido suspendida la toma del medicamento causal $(2,3,4,5)$.

Comparado con las toxicodermias clásicas, este síndrome tiene características muy específicas, en particular cronológicas, con una evolución prolongada entre la toma del medicamento y las primeras manifestaciones clínicas (2).

El objetivo de la presente revisión es promover el conocimiento de este cuadro sindrómico, aunque es poco frecuente, es necesario un rápido reconocimiento por parte del personal médico por su gran gama de afectaciones, y para esto es necesario instruir sobre las principales características epidemiológicas, fisiopatológicas y criterios clínicos para facilitar al profesional a la sospecha diagnostica, además podrá encontrar el adecuado abordaje terapéutico que rige actualmente.

\section{ANTECEDENTES}

El primer caso de síndrome de DRESS fue descrito en 1938 por Merritt y Putnam, en relación con las primeras administraciones de fenitoína como anticonvulsivante. En 1950, Chaiken y cols comunicaron un caso de erupción cutánea (dermatitis exfolialitiva) febril con hepatitis en un paciente tratado con fenitoína y lo denominaron "Dilantin sensitivity". En 1959, Sidney Saltzstein et al describieron una erupción cutánea asociada a poliadenopatías como un seudolinfoma, debido a las semejanzas clínicas e histológicas con los linfomas. Tiempo después se publicaron otros casos con diversas denominaciones, en general relacionadas con el medicamento causal, por ejemplo: síndrome por alopurinol, síndrome de hipersensibilidad a la fenitoína, síndrome por dapsona, síndrome de hipersensibilidad, síndrome del hombre rojo o síndrome parecido a la mononucleosis. A partir del año 1996 se adoptó de forma definitiva el acrónimo DRESS propuesto por Jean-Claude Roujeau. La palabra rush, sugerida inicialmente para la $\mathrm{R}$ en el acrónimo, ha sido sustituida por reacción para incluir aquellos DRESS en los que la erupción cutánea no está en primer plano. Los autores japoneses siguen fieles a la denominación "síndrome de hipersensibilidad medicamentosa" con el acrónimo DIHS, mencionado previamente. $(2,4,6,7)$.

\section{EPIDEMIOLOGÍA}

La incidencia del síndrome DRESS no se conoce realmente, pero se estima en 1/1.000-10.000 pacientes expuestos al medicamento desencadenante. Las reacciones adversas cutáneas medicamentosas afectan el 2,2 \% de los pacientes hospitalizados que reciben algún tipo de tratamiento sistémico $(2,4)$. En cuanto a las características demográficas de la población con síndrome de DRESS, la edad promedio reportada es de $40.7 \pm 20.9$ años de edad, $53 \%$ son hombres y $47 \%$ son mujeres (7).

En una revisión de la literatura realizada por Descamps et al, verificaron 131 publicaciones independientes que incluían 172 casos de síndrome de DRESS, encontrándose 44 fármacos 
relacionados con el desarrollo de esta entidad. Entre los fármacos más comúnmente relacionados se encuentran la carbamazepina (27\% de los casos), alopurinol (11-18\%), dapsona (12\%), lamotrigina $(6 \%)$, fenobarbital $(6 \%)$ y la fenitoína $(4 \%)(2,7)$.

Se encontró similitud en los distintos artículos revisados respecto a la información relacionada con la mortalidad, reportándose una prevalencia de aproximadamente $10-20 \%$, asociándose con un compromiso orgánico, siendo los más frecuentes: insuficiencia hepática, insuficiencia respiratoria por neumonitis intersticial y falla renal. En los pacientes con hepatitis grave e ictericia la mortalidad aumenta $12-50 \%(4,5,8,9,10)$.

En general, la evolución del síndrome DRESS suele ser favorable tras la interrupción del medicamento causal durante al menos 2 semanas, pero esta evolución puede estar marcada por reactivaciones y prolongarse por varios meses complicándose con la aparición de manifestaciones autoinmunitarias $(2,4)$.

\section{FISIOPATOLOGÍA}

La fisiopatología del síndrome de DRESS no está del todo claro. Sin embargo, se han implicado diferentes mecanismos o hipótesis en el desarrollo de este síndrome. A continuación, se describen las principales hipótesis sobre esta patología:

\section{1) Farmacogenética}

Deficiencia genética de enzimas desintoxicantes que conduce a la acumulación de metabolitos de fármacos que se unen a macromoléculas celulares que causan la muerte celular o inducen la respuesta inmunológica secundaria. La acumulación de estos metabolitos sería producto de una alteración, determinada genéticamente, de los mecanismos de desactivación enzimática. Esto podría explicar factores de susceptibilidad genética como, por ejemplo, un riesgo superior en personas de raza negra. Los medicamentos inductores de síndrome de DRESS más estudiados son los anticonvulsivantes metabolizados por el citocromo P450: un defecto de desactivación por el epóxido hidroxilasa o el glutatión transferasa puede conducir a la producción de metabolitos reactivos. Estos metabolitos pueden modificarse o unirse a proteínas celulares e inducir una respuesta inmunitaria. Otro modelo es el formado por las sulfamidas, grandes inductoras de síndrome de DRESS cuyo fenotipo $\mathrm{N}$-acetilador el cual se asocia a un riesgo más elevado de desarrollar este síndrome. Además, se cree que la activación eosinofílica, así como la activación de la cascada inflamatoria, puede ser inducida por la interleucina-5, la cual es liberada por células $T$ específicas contra el medicamento $(2,4,6,9,10)$.

\section{2) Asociación con reactivaciones virales}

La inmunosupresión se observa frecuentemente en el síndrome de DRESS. Los estudios han demostrado una disminución en los recuentos de linfocitos $B$ totales y los niveles de inmunoglobulina en suero, incluyendo el inicio de $\lg G$, $\lg A$ e $\lg M$, lo que demuestra una supresión inmune que puede contribuir a la reactivación frecuente del grupo del herpes virus. En el momento de la reactivación viral, se 
favorecen las células T CD8 circulantes. Las células $T$ reguladoras inicialmente aumentan en número en la circulación y en la piel, pero disminuyen en paralelo con el deterioro funcional de diferentes órganos y sistemas. La inflamación cutánea observada en las erupciones del síndrome de DRESS también puede contribuir a la inmunosupresión (6).

En los últimos años se ha demostrado que la mayoría de las manifestaciones sistémicas del síndrome de DRESS eran secundarias a la reactivación de virus del grupo herpes humano (VHH) y a la respuesta inmunitaria del huésped contra estos virus. Descamps y Rager, fueron los primeros en comunicar la responsabilidad de esta reactivación del virus herpes humano-6 (VHH-6) en una paciente de origen laosiano afectada por un síndrome de DRESS por fenobarbital complicado con un síndrome de hemofagocitosis. Esta asociación se ha confirmado luego en numerosas publicaciones de casos clínicos y series de pacientes $(2,8)$.

Autores japoneses han incluido a la reactivación del $\mathrm{VHH}-6$ en sus criterios diagnósticos para el síndrome de DRESS, o como se le conoce en Japón como DIHS. De forma paralela, se ha confirmado que otros tipos de virus como el virus del herpes $\mathrm{VHH}-7$, virus de Epstein-Barr (VEB) y citomegalovirus (CMV) podrían reactivarse y estar implicados en las manifestaciones sistémicas de los episodios evolutivos del síndrome de DRESS. Por lo tanto, se han propuesto dos situaciones: una respuesta inmunitaria dirigida contra el medicamento, con una reactivación viral secundaria a una «tormenta citocínica», o una reactivación viral precoz que explica la mayoría de las manifestaciones del síndrome de DRESS $(4,8,9,10)$.

En Francia se efectuó un amplio trabajo prospectivo de 40 casos de síndrome de DRESS para estudiar el nexo entre los medicamentos, las reactivaciones virales y la respuesta inmunitaria. En el plano virológico, pudo confirmarse que las reactivaciones de estos virus del herpes ocurrían de forma precoz durante los primeros días de la hospitalización por el síndrome de DRESS y luego de forma secuencial durante los episodios evolutivos. En el plano inmunológico, se ha demostrado que la respuesta inmunitaria linfocítica $\mathrm{T}$, conocida como de tipo $\mathrm{TH} 1$, se dirigía principalmente contra los antígenos virales.

Esto se ha estudiado mediante la secuenciación de la cadena $V \beta$ del receptor $T$ con la técnica de inmunoscopia y por estudios de tetrámeros cargados con péptidos virales. Estos trabajos han podido demostrar que los linfocitos T CD8+ fuertemente productores de factor de necrosis tumoral (TNF) alfa, interferón (IFN) gamma e interleucina 2 (IL-2) estaban presentes en la sangre y en los tejidos afectados (hígado, piel, pulmón) y dirigidos contra los péptidos del VEB $(4,9,10)$.

Las secuencias de las cadenas $V \beta$ del receptor $\mathrm{T}$ tenían, además, fuertes homologías con las secuencias señaladas en las respuestas linfocíticas durante la infección por el VEB. Estos trabajos tuvieron que haber sido efectuados con el VEB y no con el virus VHH-6 porque todavía no se conocían el repertorio y la secuencia de las cadenas $\vee \beta$ en la infección VHH-6, como 
tampoco los epítopos virales implicados. Estos resultados explican por qué el cuadro clínico del síndrome de DRESS es finalmente equivalente al de grandes reactivaciones virales como las observadas en situaciones de inmunodepresión (trasplante de órganos, pacientes en unidades de cuidados intensivos, pacientes infectados por el virus de la inmunodeficiencia humana [VIH]), a menudo con un síndrome mononucleósico inaugural, que además pueden ser considerados erróneamente como síndromes de DRESS (2).

El virus $\mathrm{VHH}-6$ es el prototipo del virus presente como una forma latente con capacidad de reactivarse, en particular en una situación de inmunodepresión. Se describen dos variantes, $\mathrm{VHH}-6 \mathrm{~A}$ y $\mathrm{VHH}$ $6 \mathrm{~B}$, que tienen el $90 \%$ de homología de secuencias.

Más del $95 \%$ de la población está infectada por este virus y posee anticuerpos contra él. Por lo general, se transmite en la infancia, entre los 6-15 meses, por gotitas de saliva. La infección por el $\mathrm{VHH}-6$ es responsable del $20 \%$ de los episodios febriles a los 6-12 meses. El virus es responsable del exantema súbito, con una incubación de 1-2 semanas y manifestaciones digestivas, rinofaríngeas, respiratorias y episodios epilépticos. Puede ser responsable de manifestaciones graves (como las observadas en el síndrome DRESS): hepatitis, meningoencefalitis, neumopatía, síndrome de hemofagocitosis, etc (2).

$\mathrm{La}$ variante $\mathrm{VHH}-6 \mathrm{~B}$ es la más frecuentemente implicada en estas manifestaciones graves. La variante VHH-6A tiene un tropismo más neurológico. Estas infecciones graves se observan principalmente en el paciente inmunodeprimido. La participación de este virus se considera en la reacción injerto contra huésped, la epilepsia, el síndrome de fatiga crónica, la esclerosis múltiple y la enfermedad de Hodgkin (2).

El patrón de la reactivación de los herpes virus es similar al observado en la enfermedad de injerto contra huésped $(\mathrm{EICH})$, lo que sugiere que el síndrome de DRESS puede parecerse a la EICH debido a que las células $T$ antivirales pueden reaccionar de forma cruzada con el medicamento y no solo surgen de la expansión oligoclonal de las células $T$ específicas contra dicho medicamento $(4,9,10)$.

El receptor de este virus (CD46) está en la superficie de numerosas células, lo que explica la posibilidad de infectar diversos órganos (piel, hígado, cerebro, intestino, pulmón, etc.), pero la infección latente se establece sobre todo en los linfocitos $\mathrm{T}$, donde el genoma viral persiste en su forma episómica. Recientemente, se ha demostrado la posibilidad de este virus de integrarse al genoma celular. Así, en el $1-3 \%$ de la población se observa una integración cromosómica del virus $\mathrm{VHH}-6$, presente en todas las células del organismo y transmitido de generación en generación. Esto probablemente sea consecutivo a una integración al ácido desoxirribonucleico (ADN) genómico de las células germinales durante la evolución. Es, por tanto, un virus no transcrito, pero la búsqueda de ADN viral por reacción en cadena de la polimerasa (PCR) en sangre total puede hacer sospechar, de manera equivocada, una fuerte viremia con más de 1 millón de copias por mililitro de sangre.

El diagnóstico de integración cromosómica puede confirmarse 
fácilmente por la presencia del genoma viral en los folículos pilosos. Las consecuencias de esta integración viral y los factores que pueden favorecer la reactivación de este virus integrado se encuentran en estudio (2).

Descamps y Rager, han emitido la hipótesis de una acción directa de algunos medicamentos sobre la reactivación y la replicación viral. Han podido demostrar in vitro la capacidad de algunos medicamentos implicados en el síndrome de DRESS (valproato de sodio, carbamazepina, amoxicilina) para aumentar la replicación del virus $\mathrm{VHH}-6$. Después de la incubación de una estirpe celular linfocítica $T$ infectada por el virus VHH-6, la replicación de $\mathrm{VHH}-6$ aumentaba en presencia del fármaco con una concentración correspondiente a las dosis «terapéuticas». Esta acción original se ha confirmado en otro modelo de estudio con las estirpes linfocíticas B establecidas a partir de linfocitos de pacientes que presentaron este síndrome (2).

En presencia de los medicamentos imputables para el síndrome de DRESS, la producción del virus VEB estaba aumentada. Puede considerarse entonces como un modelo para estudiar la posible relación entre la toma de un medicamento y la reactivación de estos virus. Desde hace muchos años se conoce la situación particular de las erupciones por amoxicilina o ampicilina en la mononucleosis infecciosa, además se ha demostrado in vitro que la amoxicilina aumentaba la replicación de los virus VHH-6 y VEB (2).

La publicación por autores japoneses del caso de un paciente que había desarrollado una erupción en el transcurso de una infección por VEB aporta argumentos a favor de esta hipótesis: la reanudación de la amoxicilina cada vez que se resolvía la erupción inducía un aumento de la viremia por VEB y una nueva erupción. El mecanismo de esta acción directa medicamento-virus se desconoce (2).

La mayoría de los medicamentos asociados al síndrome de DRESS (salazopirina, minociclina, alopurinol, etc.) son conocidos por tener propiedades inmunomoduladoras. La administración prolongada de estos tratamientos podría tener una acción inmunosupresora que favorece las reacciones virales.

Se sabe que los antiepilépticos pueden, de forma independiente para este síndrome, originar hipogammaglobulinemia. Así, en los pacientes afectados por esta patología, la hipogammaglobulinemia es más frecuente que en los hospitalizados por una eritrodermia. Estos medicamentos también podrían actuar de forma directa en el ADN viral o celular sobre los fenómenos de silenciamiento, en particular de los promotores virales. Se detallan dos mecanismos principales de control epigenético: los fenómenos de metilación y la acetilación de histonas. El valproato de sodio es conocido por ser inhibidor de las histonas deacetilasas. Esta propiedad podría favorecer una reactivación de los virus presentes en forma latente.

En esta hipótesis, una integración cromosómica del virus VHH-6 podría ser un factor de riesgo para el desarrollo de una reactivación viral. Esta hipótesis se encuentra en estudio (2). 
3) Asociación genética entre el antígeno leucocitario humano (HLA) y la reacción de hipersensibilidad a fármacos

El factor o los factores de susceptibilidad inmunogenética con riesgo de síndrome de DRESS no son bien conocidos. La primera pista vincula el medicamento con el complejo principal de histocompatibilidad HLA. En los datos clásicos sobre la fisiopatología de las toxicodermias, se señala una respuesta linfocítica $T$ inducida por el medicamento (o sus metabolitos) tras la presentación por el complejo principal de histocompatibilidad (HLA) de las células presentadoras de antígeno. Según la reactividad química, los medicamentos se clasifican en haptenos, si pueden fijarse de forma directa a una proteína sin modificación previa, o en prohaptenos, si no son reactivos y necesitan metabolización. La mayoría de los medicamentos son prohaptenos. Esto explica los numerosos trabajos dirigidos a encontrar un polimorfismo genético en las vías de desactivación de los medicamentos y el síndrome de DRESS. Para explicar las diversas situaciones se consideran cuatro modelos de presentación $(2,4,9,10)$ :

- El hapteno se presenta unido de forma covalente al péptido presentado por las moléculas HLA.

- Las uniones del hapteno son de tipo no covalente de manera independiente de los péptidos que se encuentran en la hendidura de unión de las moléculas HLA.

- El tercer modo de presentación explica que los medicamentos 0 sus metabolitos no tienen la capacidad de establecer uniones covalentes; se trata del concepto de interacción farmacológica (IF), en el que el hapteno se une directamente al receptor de los linfocitos $\mathrm{T}$.

- La unión del hapteno se produce en las hendiduras de las moléculas HLA y modifica el péptido presentado por el HLA. Datos recientes están a favor de este cuarto modo de presentación.

El síndrome DRESS se ha asociado a algunos HLA en algunos grupos étnicos y en algunos medicamentos. Así, el HLA $B^{\star} 5801$ se asocia a los DRESS por alopurinol en la etnia china Han, pero esta asociación no se observa en los japoneses. Asimismo, el HLA B*5701 se asocia a los DRESS por abacavir en pacientes de raza blanca, y su búsqueda se sugiere en la evaluación preterapéutica. Los datos más interesantes se refieren, sin embargo, a la demostración, a partir del modelo de los DRESS por abacavir asociados al HLA B*5701, de una unión directa entre el abacavir y esta molécula. Estudios moleculares y cristalográficos han demostrados uniones no covalentes del abacavir con el HLA B*5701 en la hendidura de unión próxima a la serina116. Esta unión favorece una respuesta linfocítica T CD8+ propia de algunos antígenos (péptido VTTDIQVKV), mayor que con este péptido solo. Así, la presencia del abacavir modifica el repertorio de los péptidos presentes, entre éstos los péptidos propios, alterando los mecanismos de tolerancia. Entonces se vuelven capaces de inducir una respuesta linfocítica $T$ citotóxica y producir manifestaciones de 
autoinmunidad. Es interesante señalar que este mismo HLA B*5701 también se asocia al riesgo de desarrollar hepatitis de hipersensibilidad medicamentosa por flucoxacilina. Sin embargo, no todos los pacientes con HLA ${ }^{*}{ }^{*} 5701$ desarrollan un síndrome DRESS por abacavir o una hepatitis medicamentosa por flucoxacilina, lo que habla a favor de la intervención de otros factores. También se ha demostrado que los alelos HLADR3 y HLA-DQ2 se asocian a una mayor frecuencia del síndrome DRESS inducido por carbamazepina $(2,6,8)$.

\section{DIAGNÓSTICO}

La presentación clínica del síndrome de DRESS suele comenzar entre la segunda y la octava semana a partir del contacto con el medicamento responsable e inicia con fiebre (64\%), adenopatías (56\%) y manifestaciones cutáneas de presentación variada entre las que se encuentran: eritrodermia, dermatitis exfoliativa, pustulosis, entre otras $(7,10)$.

La involucración de órganos internos ocurre en $88 \%$ de los pacientes, de estos: el $94 \%$ presenta afección hepática, manifestada como elevación de las transaminasas en $59 \%$ y hepatomegalia en $12 \%$ de los pacientes. También pueden presentar colestasis o hepatitis fulminante. El $8 \%$ presenta afección renal, ya sea nefropatía tubulointersticial con elevación de creatinina, hematuria microscópica, proteinuria e insuficiencia renal aguda.

El 5\% presenta afección pulmonar, el $2 \%$ afección del sistema nervioso central (SNC) y el $2 \%$ afección cardiaca, que puede ser pericarditis o miocarditis. La afección pulmonar consiste en neumonitis eosinofílica, caracterizada por disnea, tos seca y broncoespasmo; en la radiografía de tórax se pueden observar infiltrados simétricos bilaterales y en el lavado broncoalveolar, linfocitos y eosinofilia (7). Otros tipos de afección a un órgano interno incluyen artritis, miositis, pancreatitis, meningoencefalitis, alteraciones tiroideas (hipotiroidismo transitorio, tiroiditis) y síndrome de secreción inapropiada de la hormona antidiurética. En cuanto a anomalías hematológicas, $66 \%$ de los pacientes presenta hipereosinofilia, con cuentas absolutas de eosinófilos promedio de 3.5 a $4.1109 / \mathrm{L}$, y $27 \%$ presenta linfocitos atípicos. Otras anomalías hematológicas descritas incluyen linfopenia (51.9\%), linfocitosis atípica (18.5\%) y trombocitopenia (3.7\%) (7,10). La confirmación del diagnóstico de Síndrome DRESS debe realizarse teniendo en cuenta los diversos criterios diagnósticos (criterios de Bocquet, RegiSCAR [acrónimo del inglés Severe Cutaneous Adverse Reaction: reacciones adversas cutáneas de carácter grave] y J-SCAR), con base en los hallazgos clínicos y paraclínicos. Los criterios de Bocquet fueron propuestos originalmente como criterios absolutos para el diagnóstico de Síndrome DRESS, previos a la aparición de los criterios RegiSCAR formulados por el Registro Europeo de Reacciones cutáneas adversas severas, los cuales expanden a siete los criterios de inclusión.

Por otro lado, en los últimos años se han propuesto los criterios J-SCAR por el Comité Japonés de Búsqueda de Reacciones Cutáneas Adversas Severas los cuales incluyen el rol del virus herpes 
TABLA 1. Criterios diagnósticos para el síndrome de DRESS

\begin{tabular}{|c|c|c|}
\hline $\begin{array}{c}\text { Criterios de Bouquet, Bagot y } \\
\text { Rousseau. }\end{array}$ & Criterios SCAR-J's. $^{2}$ & Criterios del Grupo RegiSCAR. $^{3}$ \\
\hline 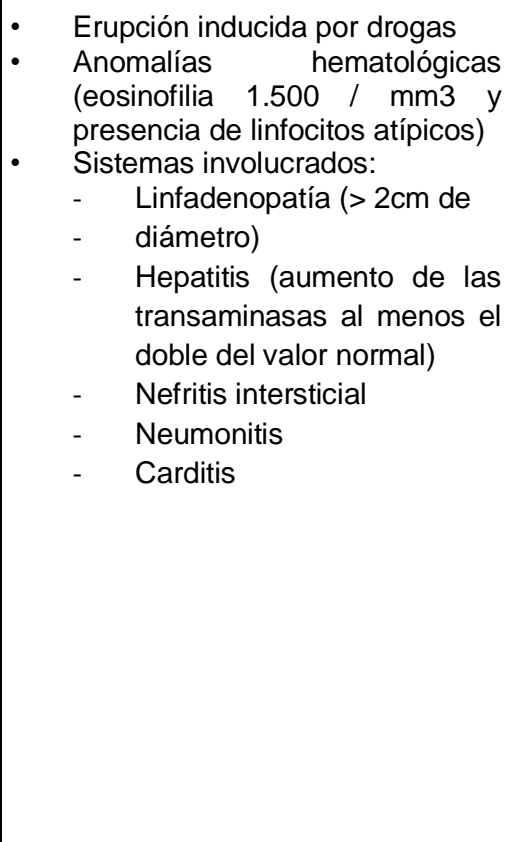 & 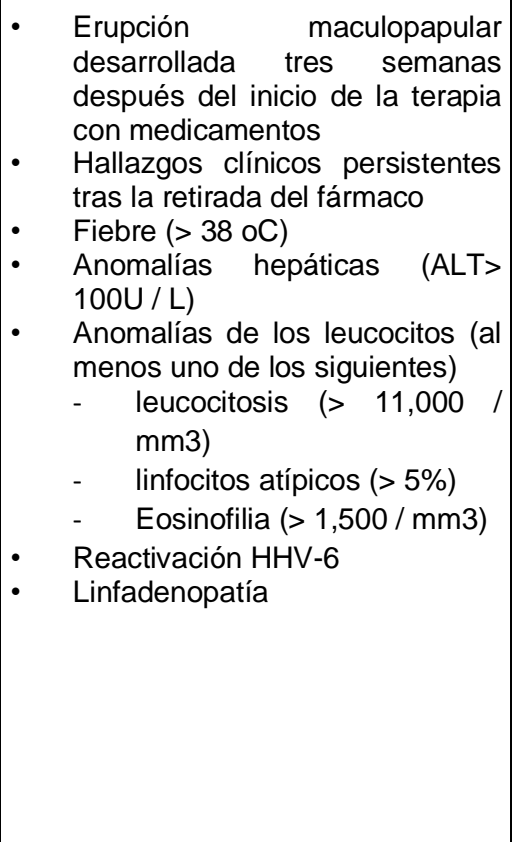 & 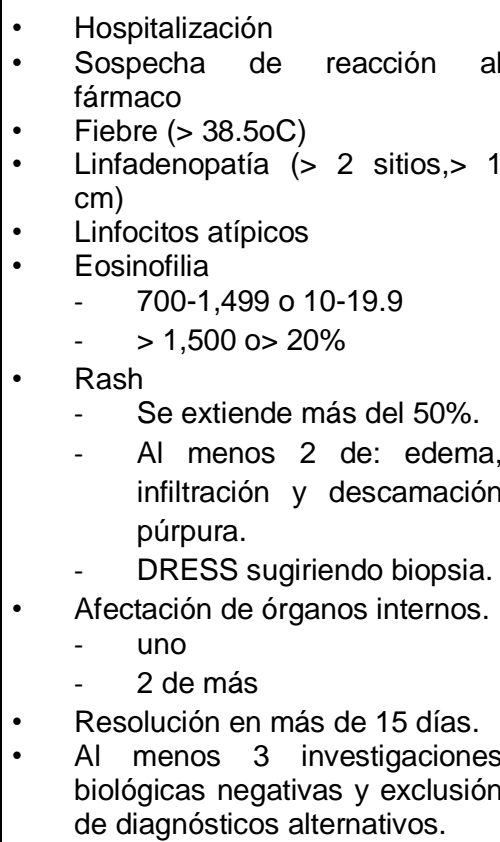 \\
\hline \multicolumn{3}{|c|}{$\begin{array}{l}\text { 1. El diagnóstico se establece cuando existen al menos tres criterios. } \\
\text { 2. El diagnóstico se establece con siete criterios (típicos) o al menos los primeros cinco criterios (atípicos). } \\
\text { 3. Puntuación final: }<2 \text { no hay DRESS; } 2-3 \text { si es posible; } 4-5 \text { caso probable, }>5 \text { caso definitivo. }\end{array}$} \\
\hline \multicolumn{3}{|c|}{ Fuente. Traducida del articulo Prevalence of DRESS Syndrome, 2014 (8 } \\
\hline
\end{tabular}

humano tipo 6 y permiten clasificar el Síndrome DRESS dentro de presentación típica o atípica $(4,11,12)$. Ver TABLA 1.

\section{DIAGNÓSTICO DIFERENCIAL}

Dentro de los diagnósticos diferenciales del síndrome de DRESS se debe considerar otras reacciones cutáneas medicamentosas potencialmente letales como el Síndrome de Stevens-Johnson (SJS), Necrolisis Epidermica Tóxica (NET), pustulosis exantemica generalizada (PEGA) y Eritrodermia (Dermatitis exfoliativa), primoinfección o reactivación viral, enfermedades del tejido conectivo, enfermedad de Still, enfermedad de Kawasaki, hemopatía, infecciones bacterianas 0 infecciones virales (Parvovirus B19, Parvovirus 6, Mononucleosis infecciosa, escarlatina, Sarampión, VHS, HIV, virus de hepatitis A y $B$, enterovirus, entre otros), síndrome hipereosinofílico idiopático, leucemia, linfoma angioinmunoblástico de células T, síndrome de Sézary y lupus cutáneo eritematoso agudo $(1,2,3,4,8,13,14)$.

\section{ABORDAJE TERAPÉUTICO}

Las medidas más importantes en la terapia del síndrome de DRESS son el reconocimiento temprano y la suspensión del fármaco sospechoso, ya que su retiro tardío está asociado a una pobre 
recuperación. El tratamiento sintomático se realiza mediante la administración de medicamentos antipiréticos y esteroides tópicos, además de la inclusión del soporte hidroelectrolítico $(10,15,16)$.

La administración de esteroides sistémicos es la terapia recomendada para síndrome DRESS y la que mejores resultados clínicos y de laboratorio proporciona. El tratamiento con esteroides sistémicos debe comenzar con un mínimo de $1.0 \mathrm{mg} / \mathrm{kg} /$ día de prednisona o su equivalente y reducir gradualmente durante 3-6 meses después de la estabilización clínica y así evitar recaídas $(2,4,10,17)$.

En los casos en que no hay mejoría o exacerbación de los síntomas con corticosteroides orales o compromiso visceral significativo, los pacientes pueden ser tratados con metilprednisolona por vía intravenosa. Se puede administrar un ciclo de metilprednisolona pulsada, $30 \mathrm{mg} / \mathrm{kg}$ por vía intravenosa durante 3 días. Se han notificado síntomas cutáneos y sistémicos significativos después de una retirada accidental 0 una rápida reducción de la dosis de corticosteroides. Aunque la terapia con esteroides es generalmente efectiva en el contexto agudo, su efecto en el curso de la enfermedad a largo plazo es desconocido. Durante el tiempo, que se reciba el tratamiento con esteroides se recomienda el conteo completo de células sanguíneas, las pruebas de función hepática, valoración de los ganglios linfáticos y otras pruebas de laboratorio específicas para el organismo deben controlarse cuidadosamente para detectar una posible recaída, y las dosis de esteroides deben ajustarse en consecuencia (7).

Se han propuesto otros tratamientos (inmunosupresores como la ciclosporina, plasmaféresis, ciclofosfamida, ciclosporina, interferones, micofenolato y rituximab) pueden ser potencialmente beneficiosas tal como lo demuestra un caso reportado por Zuliani et al., donde un síndrome de DRESS secundario al uso de vancomicina que no respondió a terapia con esteroides, fue tratado de manera exitosa con la administración de ciclosporina durante cinco días. Asimismo, Laban et al. informaron un caso de DRESS corticorresistente asociado a nefritis intersticial aguda que se trató exitosamente con 6 meses de ciclofosfamida oral $(2.4,10)$.

También se ha propuesto a la $\mathrm{N}$ acetilcisteína en dosis altas, precursor de glutatión, que es una molécula implicada en la vía de desintoxicación de varios medicamentos y ofrece un efecto inmunomodulador por la inhibición de citoquinas inflamatorias y la expresión de ICAM-1 en queratinocitos, que se ha utilizado especialmente en el síndrome de DRESS inducido por anticonvulsivantes, el cual puede ayudar en la desintoxicación de la droga; sin embargo, no existen ensayos clínicos que confirmen su eficacia. Medicamentos antivirales, como el valganciclovir, pueden ser útiles para prevenir o reducir al mínimo las complicaciones relacionadas con la reactivación del HHV-6 $(8,10)$.

En la literatura se reporta el uso de inmunoglobulinas cuando la terapia con corticosteroides no responde; sin embargo, Joly et al. no encuentran ningún beneficio con esta terapia, sino 
que, por el contrario, registraron la presencia de severos efectos adversos (10).

Recientemente, Leman et al. describieron un tratamiento exitoso de un caso de DRESS con un inhibidor del factor de necrosis tumoral alfa (TNF- $\alpha$ ) que contiene carbonato de litio. Sin embargo, este es el único informe sobre el tratamiento con DRESS con un inhibidor de TNF-a, por lo que se requieren estudios clínicos adicionales (18).

\section{CONCLUSIÓN}

El síndrome de DRESS es una entidad toxicodérmica grave de tipo idiosincrático caracterizado por fiebre, eosinofilia marcada, linfadenopatías o incluso puede evolucionar a una afección sistémica. La patología está determinada por la hipersensibilidad cutánea asociada a múltiples fármacos, y al ser un cuadro sindrómico con presentación variable es fundamental realizar una detallada historia clínica, examen físico e historia farmacológica completa.
Es de suma importancia tener conocimiento del síndrome de DRESS en nuestra práctica clínica, debido a que existen factores que pueden aumentar la exacerbación de esta patología como lo es la automedicación. Con este reporte, el profesional médico podrá complementar la sospecha clínica con los criterios diagnósticos actuales con el fin de definir el cuadro sindrómico y así brindar un abordaje terapéutico adecuado, de forma temprana, y evitar la aparición de complicaciones más severas.

Se espera que con este reporte se logre comunicar a la población en general la importancia de recordar e informar al profesional en salud sobre los medicamentos que son previamente utilizados, esto con el fin de contribuir con la sospecha diagnostica de este cuadro sindrómico.

Por último, recomendamos a todo el personal de salud en enfatizar el reporte de efectos secundarios o reacciones alérgicas con el uso de cualquier fármaco para que así sean notificados a los distintos entes farmacéuticos y posteriormente documentados en la literatura en salud.

\section{REFERENCIAS}

1. Wu S. Síndrome de DRESS y Síndrome de Steven Johnson. Med. leg. Costa Rica. 2011 Marzo; 28(1): 65-69. Disponible en: http://www.scielo.sa.cr/scielo.php?script=sci arttext\&pid=S140900152011000100008\&lng=en

2. Descamps V, Rager S. Síndrome DRESS. EMC - Dermatología. 2016 Septiembre; 50(3): 19.http://dx.doi.org/10.1016/S1761-2896(16)79892-X

3. Sosa A, Ordóñez M, Figueroa E. Síndrome de DRESS: presentación de caso y revisión de literatura. REV MED HONDUR. 2017; 85(3 y 4): 116-119. Disponible en:http://www.bvs.hn/RMH/pdf/2017/pdf/Vol85-3-42017-12.pdf

4. González A, Luque J, Yasnó D, Tibaduiza A, Chacón L. Síndrome Dress A propósito de un reporte de caso en el Hospital Militar Central. Neurociencias en Colombia. 2015 Diciembre; 22(4): 301-307 Disponible en: http://www.acncx.org/images/revistas/pdf/diciembre2015.pdf 
5. García M, Valencia J. Síndrome de Dress: presentación de un caso clínico. Med U.P.B. 2016; 35(1): 4751. http://dx.doi.org/10.18566/medupb.v35n1.a07

6. Husain Z, Reddy B, Schwartz R. DRESS syndrome Part I. Clinical perspectives. J AM ACAD DERMATOL. 2013 Mayo; 68(5): 693.e1-693.e14.https://doi.org/10.1016/j.jaad.2013.01.033

7. Muciño J, Díaz M, Briones CG, Guerrero A, Sandoval OI, Sáenz AG, Briones JC. Síndrome de DRESS. Revista Médica del Instituto Mexicano del Seguro Social. 2013; 51(3): 330-335. Disponible en: https://www.medigraphic.com/cgi-bin/new/resumen.cgi?IDARTICULO=41731

8. López E, Blancas L, Rodríguez K, Gaspar A, O'Farrill P, Amaya A, et al. Prevalence of DRESS Syndrome. Revista Alergia México. 2014; 61: 14-23. Disponible en:http://revistaalergia.mx/ojs/index.php/ram/article/view/16

9. Kremić Z, Mijušković Z, Sekulović L. Dress Syndrome - A Case Report. Serbian Journal of Dermatology and Venereology 2016; 8(2): 95-100. https://doi.org/10.1515/sjdv-2016-0009

10. Londoño $H$, Guerra M, Hernández $C$, Hoyos D, Jiménez K. DRESS syndrome induced by anticonvulsants and fulminant hepatic failure. Rev. Fac. Med. 2017; 65(1): 165168.http://dx.doi.org/10.15446/revfacmed.v65n1.51919

11. Fernández MM, Ramírez A, Guerrero I, López A. Síndrome DRESS. Dermatol Rev Mex. 2018 noviembre diciembre; 62(6): 522-528. Disponible en:http://www.medigraphic.com/pdfs/derrevmex/rmd2018/rmd186i.pdf

12. Fernández de Córdova LR, Guzmán KA, Fernández de Córdova JC. Síndrome DRESS o reacción a fármacos con eosinofilia y síntomas sistémicos asociada con el consumo de fármacos antituberculosos. $\begin{array}{lllll}\text { Revista } \quad \text { Alergia } & \text { 2015; }\end{array}$ en:http://revistaalergia.mx/ojs/index.php/ram/article/view/74/161

13. Silva M, Ortiza E, Rojas MJ, Muñoza D. Síndrome de sensibilidad a fármacos con eosinofilia y síntomas sistémicos en pediatría. Rev Chil Pediatr. 2017; 88(1): 158163.http://dx.doi.org/10.1016/j.rchipe.2016.05.010

14. Hay C, Shepard J, Hyle E, Duncan L. Case 23-2014: A 41-Year-Old Man with Fevers, Rash, Pancytopenia, and Abnormal Liver Function. N Engl J Med 2014; 371: 358366.https://doi.org/10.1056/NEJMcpc1404140

15. Da Silva S, Pereira M, Carneiro L, Borowiak D. Drug reaction with eosinophilia and systemic symptoms (DRESS syndrome). Rev Assoc Med Bras 2016; 62(3): 227-230.http://dx.doi.org/10.1590/18069282.62.03.227

16. García M, Valencia J. Síndrome de Dress: presentación de un caso clínico. Med U.P.B. 2016; 35(1): 4751. http://dx.doi.org/10.18566/medupb.v35n1.a07

17. Díaz V, Tirado A, Ponce R. Clinical, aetiological and therapeutic findings in Drug Reaction with Eosinophilia and Systemic Symptoms (DRESS) syndrome, four years experience in a third-level Mexican hospital. Rev Med Hosp Gen Méx. 2016; 79(2): 55-62.http://dx.doi.org/10.1016/j.hgmx.2015.08.004

18. Watanabe H. Recent Advances in Drug-Induced Hypersensitivity Syndrome/ Drug Reaction with Eosinophilia and Systemic Symptoms. Journal of Immunology Research. Marzo 2018; Article ID 5163129. https://doi.org/10.1155/2018/5163129 